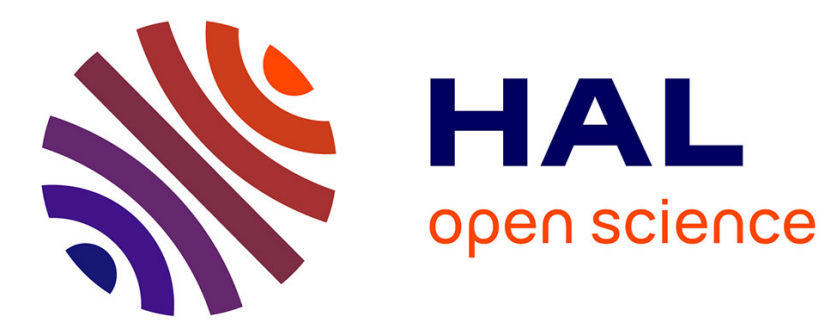

\title{
The Electromagnetic Cylindrical Compression: A Tool to Test Behavior Modeling under Large Strain at High Strain Rate
}

\author{
J. Petit, Y. Alexeev, S. Ananiev, M. Kazeev
}

\section{- To cite this version:}

J. Petit, Y. Alexeev, S. Ananiev, M. Kazeev. The Electromagnetic Cylindrical Compression: A Tool to Test Behavior Modeling under Large Strain at High Strain Rate. Journal de Physique IV Proceedings, 1997, 07 (C3), pp.C3-109-C3-114. 10.1051/jp4:1997321 • jpa-00255478

\section{HAL Id: jpa-00255478 https://hal.science/jpa-00255478}

Submitted on 1 Jan 1997

HAL is a multi-disciplinary open access archive for the deposit and dissemination of scientific research documents, whether they are published or not. The documents may come from teaching and research institutions in France or abroad, or from public or private research centers.
L'archive ouverte pluridisciplinaire HAL, est destinée au dépôt et à la diffusion de documents scientifiques de niveau recherche, publiés ou non, émanant des établissements d'enseignement et de recherche français ou étrangers, des laboratoires publics ou privés. 


\title{
The Electromagnetic Cylindrical Compression: A Tool to Test Behavior Modeling under Large Strain at High Strain Rate
}

\author{
J. Petit, Y.A. Alexeev*, S.P. Ananiev* and M.N. Kazeev* \\ DGA, Centre d'Études de Gramat, 46500 Gramat, France \\ * NFI, Kurchatov Institute, Kurchatov Sq., Moscow 123182, Russia
}

\begin{abstract}
The material behavior at high strain rate $\left(>10^{4} \mathrm{~s}^{-1}\right)$ and large strain $(>50 \%)$ is unattainable with usual tests. So it is deduced extrapolating results from tensile, compression, torsion, plate impact or pressure shear experiments. Exploitation of an electromagnetic cylindrical compression test allows to validate this extrapolation. It allows to analyze the coupling of the effects of plastic strain, plastic strain rate and temperature or also, for example, the effect of a viscous drag dislocation term. The principle and the limits of this exploitation by experimentation-1D calculation comparisons are illustrated with the first tests obtained on copper tubes.
\end{abstract}

\begin{abstract}
Résumé : Le comportement des matériaux à haute vitesse de déformation (>10 $\mathrm{s}^{-1}$ ) et grande déformation $(>50 \%)$ est inaccessible aux essais courants. Il est donc déduit en extrapolant les résultats des essais de traction, compression, torsion et impacts plans ou inclinés. L'exploitation d'un essai de compression cylindrique électromagnétique permet de tester la validité de cette extrapolation. Elle permet d'analyser le couplage des effets de la déformation plastique, de la vitesse de déformation plastique et de la température ou encore, par exemple, de tester l'influence d'un terme de frottement visqueux des dislocations. Le principe et les limites de l'exploitation par comparaisons expérience-calcul 1D sont illustrés avec les premiers résultats obtenus sur des tubes de cuivre.
\end{abstract}

\section{INTRODUCTION}

Numerical simulation is widely used to help experimental studies and also to study involved physical processes because it is the only way giving access to many non measurable quantities in numerous configurations (stresses, thermomechanical state of materials ...). In such a case, it allows a best understanding of phenomena and, subsequently, an optimized use of the constitutive materials. Analysis of numerical simulation results is only reliable if the modeling selected for materials has been validated in the corresponding field of use. This paper presents a validation method of behavior models at high strain rate through the analysis of electromagnetic cylindrical compression experiments.

After presentation of the principle of analysis, the following section will describe the experimental apparatus and its performances. Analysis of electromagnetic cylindrical compression experiments in order to validate behavior models will be illustrated in the following sections where the limits of this approach will be addressed.

\section{PRINCIPLE OF ANALYSIS}

The experiment of electromagnetic cylindrical compression does not directly give access to a stress-strain curve. The records obtained during experiments correspond to measurements of the magnetic field outside the tube and of the inner radius of the tube versus time. A record example of these two parameters is presented in figure 1. The field is applied during the whole tube motion. Then, there is no 'free flight' phase during which an energy balance could allow determination of an average value of the yield strength as it is performed in the case of ring expansion tests [1,2].

On the other hand, the electromagnetic cylindrical compression experiment can be used as an appropriate tool to validate behavior models by experimentation-calculation comparisons in domains that are inaccessible to conventional experiments. For a given and measured magnetic field, the evolution of the inner radius in such a simulation mainly depends on the selected behavior model. Comparison of the 
'inner radius versus time' curves obtained through experimentation and calculation allows the validation of the behavior model in the domain of stress reached.

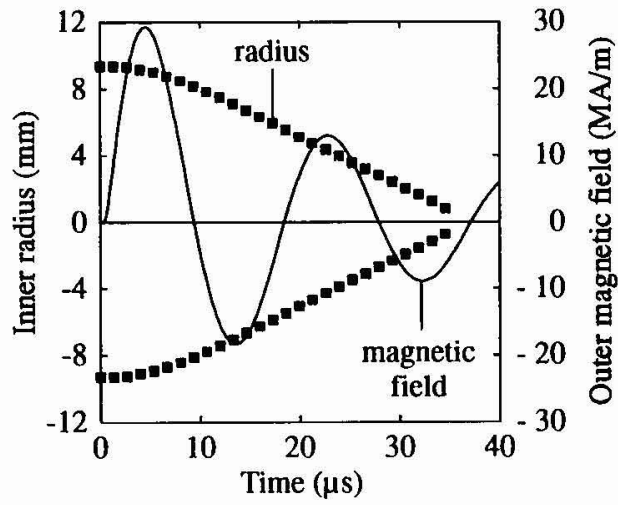

Figure 1 : Inner radius and outer magnetic field during an electromagnetic cylindrical compression.

(Records of the experiment with the tube of 1-mm thick wall presented in a next section)

\section{EXPERIMENTAL APPARATUS}

The experimentation was carried out at the Kurchatov Institute on the TROB-100 apparatus [3] which is a pulsed current generator based on a capacitive low-inductance energy storage. The total capacity of the TROB-100 is $320 \mu \mathrm{F}$, its intrinsic inductance is about $5 \mathrm{nH}$ and its charging voltage is up to $25 \mathrm{kV}$. The stored energy is up to $100 \mathrm{~kJ}$. With the inductor, the total inductance is about 26-28 $\mathrm{nH}$, frequency of oscillations in the current is about $3.510^{5} / \mathrm{s}$ and damping is $510^{4} / \mathrm{s}$. The capacitor bank is discharged through a massive single-turn solenoid (inductor) in the middle of which a pulsed magnetic field is produced with an amplitude up to $40 \mathrm{MA} / \mathrm{m}$ (500 $\mathrm{kOe}$ in cgs/emu units) for fast tubes deformation. The inductor, the sample and the diagnostic instrumentation are shown in figure 2.
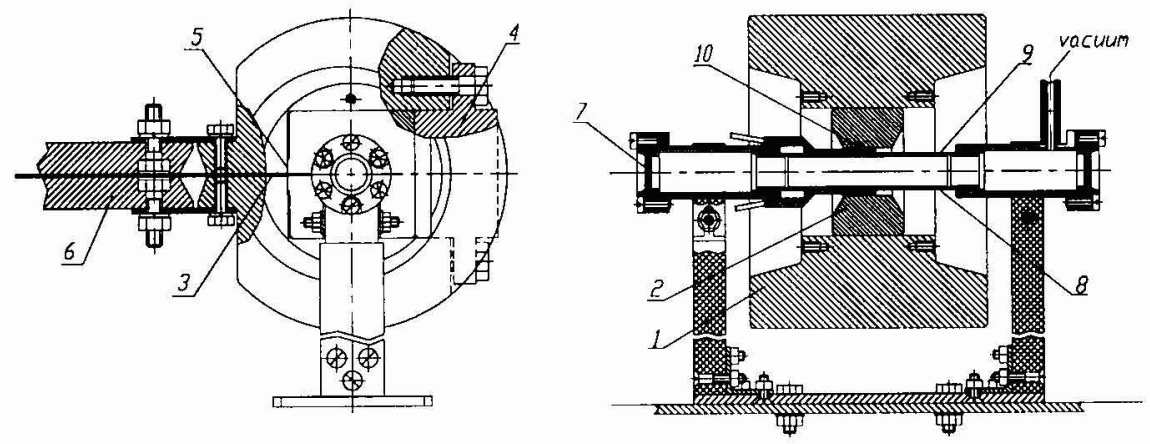

Figure 2 : Drawing of the experiment. 1 - massive bandage, 2 - inductor, 3 - insulation, 4 - clamp,

5 - copper spacer, 6 - collector of current, 7 - window, 8 - vacuum chamber, 9 - sample, 10 - magnetic probe.

The magnetic field in the single-turn inductor is asymmetric in the azimuthal direction. Close to the inductor cut, the magnetic field is smaller than on the opposite side. The azimuthal magnetic ficld inhomogeneity results in the asymmetric tube compression. To reduce again the magnetic field inhomogeneity in the gap between the tube and the inductor, the used inductors had a special configuration of their lateral surfaces. The field homogeneity can be evaluated at $2 \%$ for the inductor used for the slowest tube compression presented here and about 4-5\% for the other ones. 
The magnetic probes, 10, were located in the gap between the inner inductor surface and the chamber. In the proposed experiments, only one probe set on the opposite side of the inductor cut was used. The magnetic field magnitude was calculated by integrating the magnetic probe signal. The accuracy of the magnetic field magnitude that depends on the product $\mathrm{nS}$ of the magnetic probes one ( $\mathrm{n}$, number of turns and $\mathrm{S}$, their section). It was no worse than $2.5-3 \%$ for the experiments presented here.

The dynamics and compression symmetry of the tubes were observed with respectively streak and frame cameras. The accuracy of synchronization is about $300 \mathrm{~ns}$, the time resolution of $r_{i}(t)$ measurement is about $20 \mathrm{~ns}$ and the measurement accuracy of the inner radius is no worse than $0.25 \mathrm{~mm}$ for the streak camera scanning. The measurements performed with the frame camera show that the asymmetry during this experiment is no worse than $6 \%$ when the inner radius is greater than $2.5 \mathrm{~mm}$. This asymmetry remains confined close the inductor cut and its influence is reduced in the measurement plane of the streak camera which is perpendicular to the inductor cut.

\section{METHODS OF NUMERICAL SIMULATION}

The numerical simulation of the electromagnetic cylindrical compression experiment was performed with UNIDIM [4], a unidimensional fast dynamics code inspired from WONDY [5] and used here in its cylindrical configuration. This code was adapted to take into account electromagnetic stress : Laplace volume forces were added in the momentum conservation equation and heating through Joule effect was introduced in the energy conservation equation [6].

From Maxwell equations :

$$
\operatorname{rot} \overrightarrow{\mathrm{H}}=\vec{j} \text {, rot } \overrightarrow{\mathrm{E}}=-\frac{\overrightarrow{\partial B}}{\partial \mathrm{t}} \text { and } \overrightarrow{\mathrm{B}}=\mu \overrightarrow{\mathrm{H}}
$$

where $\mathbf{H}$ is the magnetic field, $\mathrm{j}$ the current density, $\mathrm{E}$ the electric field, $\mathrm{B}$ the magnetic induction and $\mu$ is the magnetic permeability ; and from Ohm's law :

$$
\vec{E}+\vec{v} \times \vec{H}=\frac{1}{\sigma} \vec{j}
$$

where $\mathrm{v}$ is the particle velocity and $\sigma$ the electric conductivity ; the Lagrangian time derivative of the magnetic field can be expressed in the cylindrical case with a magnetic field unidirectional along the axis of revolution $\mathrm{z}$ :

$$
\frac{\mathrm{DH}_{\mathrm{z}}}{\mathrm{Dt}}=\frac{1}{\sigma \mu} \frac{\partial^{2} \mathrm{H}_{\mathrm{z}}}{\partial \mathrm{r}^{2}}+\frac{1}{\sigma \mu}\left(\frac{1}{\mathrm{r}}-\frac{1}{\sigma} \frac{\partial \sigma}{\partial \mathrm{r}}\right) \frac{\partial \mathrm{H}_{\mathrm{z}}}{\partial \mathrm{r}}-\left(\frac{\mathrm{v}_{\mathrm{r}}}{\mathrm{r}}+\frac{\partial \mathrm{v}_{\mathrm{r}}}{\partial \mathrm{r}}\right) \mathrm{H}_{\mathrm{z}}
$$

Two boundary conditions are necessary to resolve this equation. The first one is provided by the measurement of the field outside the tube. The second one is given by the equations of continuity of the electric field inside the tube that lead to :

$$
\left.\frac{\mathrm{DH}_{\mathrm{z}}}{\mathrm{Dt}}\right|_{\mathrm{r}_{\mathrm{i}}}=\left.\frac{2}{\sigma \mu \mathrm{r}_{\mathrm{i}}} \frac{\partial \mathrm{H}_{\mathrm{z}}}{\partial \mathrm{r}}\right|_{\mathrm{r}_{\mathrm{i}}}-\frac{2 \mathrm{v}_{\mathrm{r}_{\mathrm{i}}}}{\mathrm{r}_{\mathrm{i}}} \mathrm{H}_{\mathrm{zr}_{\mathrm{i}}}
$$

A Crank-Nicholson writing in the initial Lagrangian space that remains steady, gives for equation (5) a tridiagonal matrix whose resolution can be provided by a Cholesky method. When the magnetic field is known, the Laplace forces per unit of volume, $f_{r}$, and the increase of internal energy during the time interval dt due to Joule effect, $\mathrm{dw}_{\mathrm{J}}$, can be calculated :

$$
\mathrm{f}_{\mathrm{r}}=-\mu \frac{\partial \mathrm{H}_{\mathrm{z}}}{\partial \mathrm{r}} \mathrm{H}_{\mathrm{z}}, \mathrm{dw} \mathrm{w}_{\mathrm{J}}=\frac{\mathrm{dt}}{\sigma \rho}\left(\frac{\partial \mathrm{H}_{\mathrm{z}}}{\partial \mathrm{r}}\right)^{2}
$$

where $\rho$ is the material density. Two models of behavior are tested in this study. They allow to determine the threshold stress of plastic flow :

$$
\mathrm{Y}=\mathrm{f}\left(\varepsilon_{\mathrm{p}}, \dot{\varepsilon}_{\mathrm{p}}, \mathrm{T}\right)
$$

where $\mathrm{Y}$ is the value of the equivalent threshold stress of plastic flow (for a model of perfect plastic behavior, this value is constant), $\varepsilon_{\mathrm{p}}$ the equivalent plastic strain, $\dot{\varepsilon}_{\mathrm{p}}$ the equivalent plastic strain rate and 
$\mathrm{T}$ the temperature. These equivalent values are defined by applying the Von Mises's criterion and assuming the tensile test as reference :

$$
\sqrt{\frac{3}{2} S_{i j} S_{i j}} \leq Y, d \varepsilon_{p}=\sqrt{\frac{2}{3} d \varepsilon_{i j}^{p} d \varepsilon_{i j}^{p}}
$$

where $S_{\mathrm{ij}}$ correspond to terms of the deviatoric part of the stress tensor and $d \varepsilon_{\mathrm{ij}}^{\mathrm{p}}$ correspond to terms of the tensor of plastic-strain increments.

\section{COMPARISON EXPERIMENT-CALCULATION}

Experiments were performed on tubes manufactured from an OFE-OK grade copper rod. The average initial grain size was $50 \mu \mathrm{m}$ from micrograph observations. The inner diameter of the tubes remained equal to $18.6 \mathrm{~mm}$ for every experiment. Tubes of different wall thicknesses $(1.5,1.0$ and $0.5 \mathrm{~mm})$ were used to investigate three different domains of strain rate (figure 3 ).

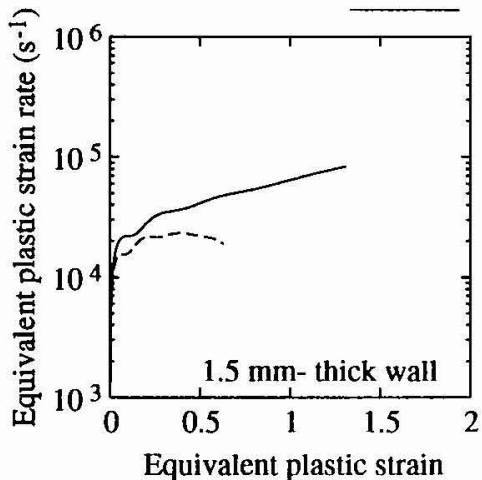

Equivalent plastic strain

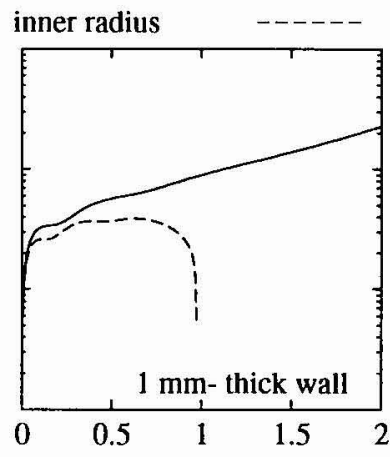

Equivalent plastic strain

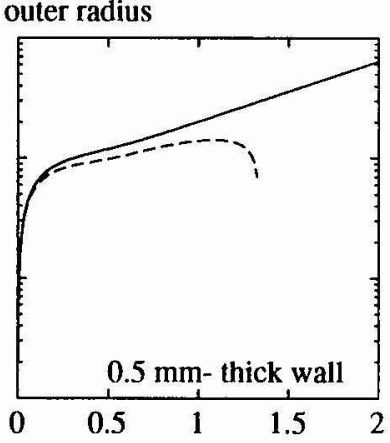

Equivalent plastic strain

Figure 3 : Equivalent plastic strain and strain rate.

In numerical simulations, the initial meshing was regular with a size of $0.01 \mathrm{~mm}$ fitted to an accurate numerical processing whatever the wall thickness of the tube may be. Two behavior models of copper were tested to evaluate the interest of the analysis presented here : the model proposed by Zerilli and Armstrong in its first version [7] and the next one including a term of dislocation drag that gives a sharp increase of the stress at high strain rate [8]. The copper used in this study was not characterized and the primary coefficients published with these models were used as default values. Only the true grain size was taken into account. The experiment-1D numerical result comparisons are presented in the figure 4.

- experimental data,

Y Z-A without drag dislocation, Y A-Z with drag dislocation.
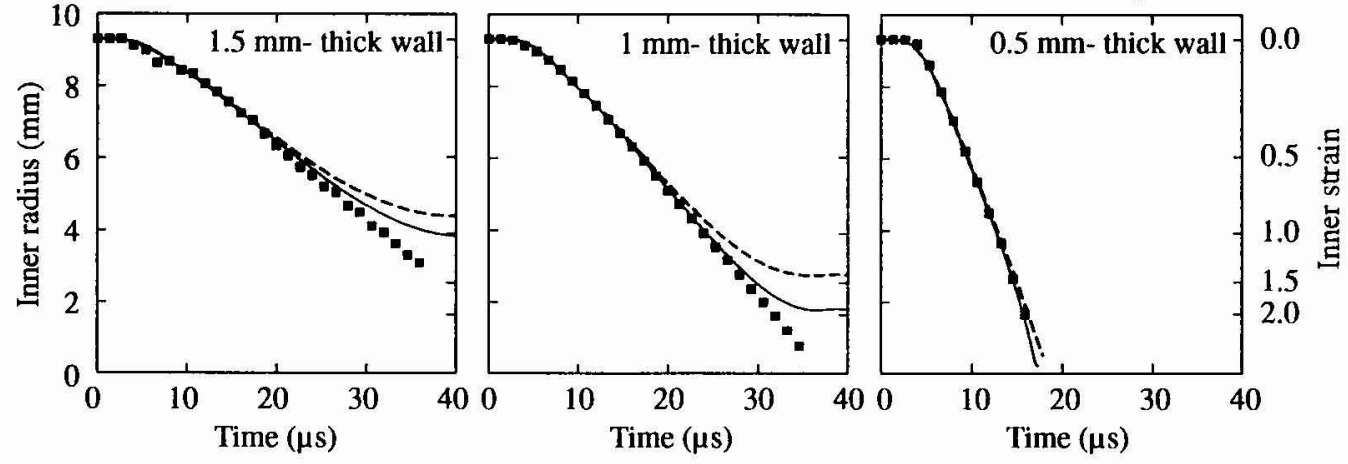

Figure 4 : Test of the models for the different wall thicknesses. 
When the wall is too thin $(0.5 \mathrm{~mm})$, the both models give the same result. Conversely, with the thickest tubes, the tested models clearly exhibit a more or less large overestimation of the threshold stress modeling of the plastic flow. Simulations performed with different values of the yield strength in a model of perfectly plastic behavior allow to assess this overestimation and consequently the accuracy of the model testing (figure 5).
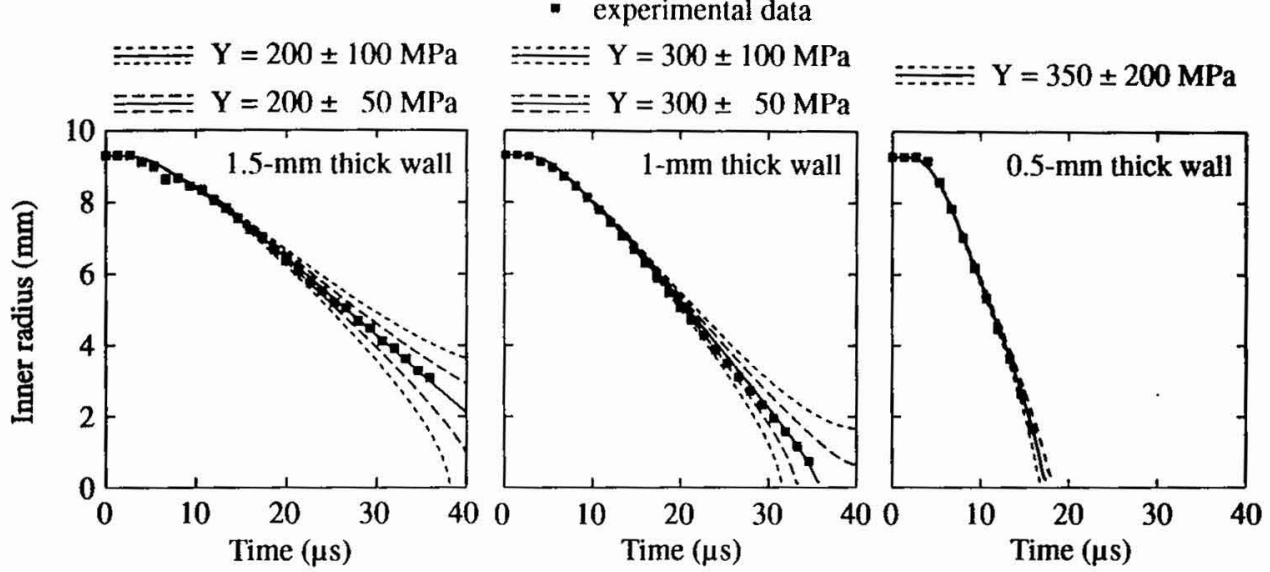

Figure 5 : Test of perfectly plastic models.

Results presented in the both figures 4 and 5 show that :

- in the fastest tube compression, the plastic work is certainly low compared to the kinetic energy and consequently the tube closure is not very sensitive to the behavior model. It is a limit of this kind of analysis.

- with the slowest tube compressions presented here, it is possible to evaluate behavior models and to clearly observe the effect of an error of $50 \mathrm{MPa}$ on the mean threshold stress.

The magnetic field measurement is employed as initial data in the numerical simulation. Its relative error of measurement can be evaluated to $3 \%$ for this series of experiments achieved with only one probe. Numerical simulations with a given perfect plastic behavior were implemented to evaluate its influence on every experiment (figure 6). These last results compared to the preceding ones (figure 5) show that the effect of a $3 \%$ error on the field is, for the slowest experiments, equivalent to an error of about $20 \%$ on the yield strength. Enhancing the accuracy of the field measurement is then indispensable for a more reliable validation of the behavior models. To reach an accuracy of $1 \%$ is feasible and seems enough (figure 6).

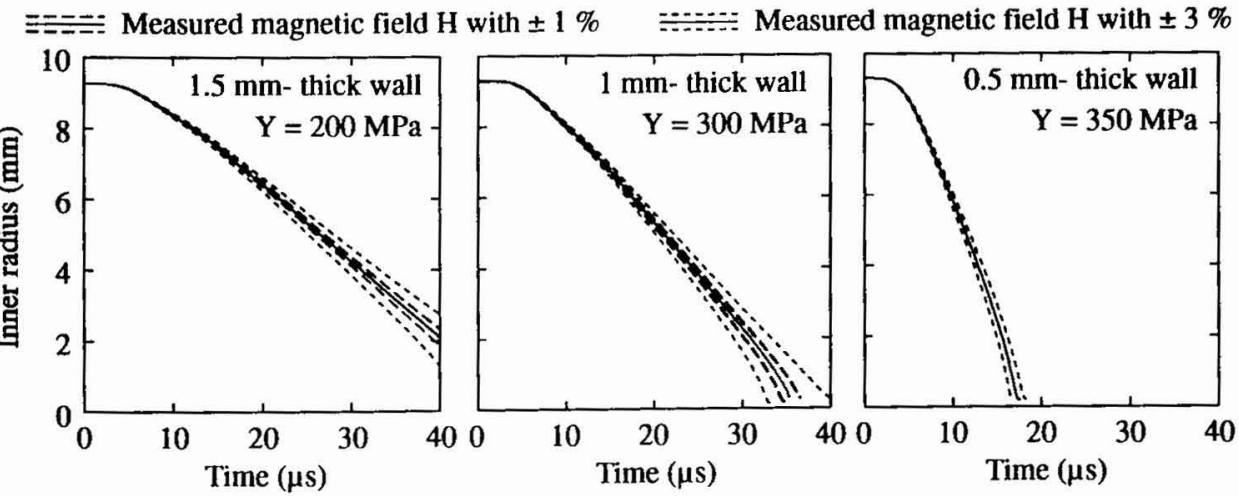

Figure $6:$ liffect of an error on the measurement of the magnetic field. 
The results of numerical simulation were used in this study to evaluate the validity of the behavior models. Several calculations were performed to make sure that an inaccuracy of the other physical parameters of the material modeling cannot distort the study on behavior models. Pressure remains low then an inaccuracy on the state equation coefficients has low effect on final results. The influence of inaccuracies in the modeling of specific heat, shear modulus, electric or thermal conductivity was als( tested : it remains minimal as long as the material is not subject to a phase change.

\section{CONCLUSION}

The results obtained in this first study with copper as training material demonstrate the interest of experimentation-simulation comparisons of the electromagnetic cylindrical compression test in order 10 validate behavior models in the field of strain greater than $50 \%$ and strain rate higher than $10^{4} / \mathrm{s}$.

The heating due to JOULE effect is indissociable from the electromagnetic stress. This characteristic can be an other interest presented by this experiment because high temperatures can be reached without any heating and, subsequently, without any microstructural modifications (grain size increase, tempering after quenching ...) before testing.

The pursuit of the evaluation work of this method requires the testing of a perfectly known material whose behavior model coefficients have been determined from conventional experimental results. $\Lambda$ comparative evaluation of the proposed method with the TAYLOR's test that is often used to validale behavior models could be advantageously performed on a same material to compare of their respective advantages.

This experiment of electromagnetic cylindrical compression is above all fitted to electric conductor materials. However, non conductive materials could be tested if they are coated with a conductive material whose behavior model would have been first validated.

\section{Acknowledgments}

The authors thank Yu. S. Tolstov of RRC "Kurchatov Institute" for computer processing of experimental data and D. Desestrets of Centre d'études de Gramat for his help in numerical simulation implementation.

\section{REFERENCES}

[1] R.H. Warnes, R.R. Karpp, P.S. Follansbee, "The freely expanding ring test - A test to determine material strength at high strain rates", Journal de Physique, Colloque C5, sup. au n ${ }^{\circ}$, Tome 46, pp C5-583 C5-590, 1985.

[2] W.H. Gourdin, J. Appl. Phys., Vol 65, N², pp 411-422, 1989.

[3] Yu. A. Alexeev, M.N. Kazeev, V.F. Demichev, V.I. Sinitsin, Physics and Technology R\&I) at the Laboratory of Pulsed Physical Studies, Plasma Physics Division, Preprint IAE-5473/7, Moscow, 1992.

[4] P.L. Hereil, "UNIDIM : un code monodimensionnel aux différences finies", CEG Technical Report, to be published.

[5] M.E. Kipp, R.J. Lawrence, "WONDY V : A One-Dimensional Finite-Difference Wave-Propagation Code", Sandia National Laboratories Albuquerque, SAND--81-0930 Report, 1982.

[6] H. Knoepfel, Pulsed High Magnetic Fields, North Holland Publishing Company, Amsterdam, 1970.

[7] F.J. Zerilli, R.W. Armstrong, J. Appl. Phys., Vol 61, N5, pp 1816-1825, 1987.

[8] R.W. Armstrong, F.J. Zerilli, "IDislocation mechanics based analysis of materials dynamics behavior", Journal de Physique, Colloque C3, sup. au nº, Tome 49, pp C3-529 C5-534, 1988. 